\section{Commentary: Elegantly confirming what we might predict}

\author{
Erle H. Austin III, MD
}

Magnetic resonance (MR) imaging is an important modality for structural assessment of the central nervous system. Most of us have been unaware that in addition to imaging, MR can also be used to assess metabolites in neural tissue. Proton MR spectroscopy is a clinic-ready technique that can noninvasively measure multiple central nervous system metabolites, including creatine, lactate, and glucose in designated portions of living brain tissue. Recognizing the potential of this elegant technique, Hanley and colleagues ${ }^{1}$ applied proton MR spectroscopy to assess in vivo brain metabolism in piglets utilizing their well-established neonatal bypass model that compares antegrade cerebral perfusion to deep hypothermic circulatory arrest (DHCA). Five neonatal piglets were placed on cardiopulmonary bypass and cooled to $18^{\circ} \mathrm{C}$ and subjected to an hour of total body circulatory arrest. Two of the 5 received antegrade cerebral perfusion and all 5 underwent MR scanning during the session. Figure 3 in the article by Hanley and colleagues ${ }^{1}$ provides a significant comparison demonstrating major increase in brain lactate and decrease in brain glucose in the DHCA piglets with minimal change noted in the antegrade perfusion animals. One might be critical of the small number of piglets in each group, but the differences are striking and support the clinical practice of selective cerebral perfusion.

I do not think that these findings are surprising because one would expect that the interruption of perfusion and oxygen delivery to brain tissue would result in anaerobic metabolism manifest in a significant increase in lactate and decrease in glucose. One would also expect recovery of lactate and glucose levels with resumption of brain flow

\footnotetext{
From the Department of Cardiovascular and Thoracic Surgery, University of Louisville, Norton Children's Hospital, Louisville, Ky.

Disclosures: Author has nothing to disclose with regard to commercial support.

Received for publication Nov 1, 2019; accepted for publication Nov 1, 2019; available ahead of print Nov 22, 2019.

Address for reprints: Erle H. Austin III, MD, Department of Cardiovascular and Thoracic Surgery, University of Louisville, Norton Children's Hospital, 201 Abraham Flexner Way, Suite 1200, Louisville, KY 40202 (E-mail: erle.austin@ ulp.org).

J Thorac Cardiovasc Surg 2020;160:e229

$0022-5223 / \$ 36.00$

Copyright (c) 2019 by The American Association for Thoracic Surgery

https://doi.org/10.1016/j.jtcvs.2019.11.008
}

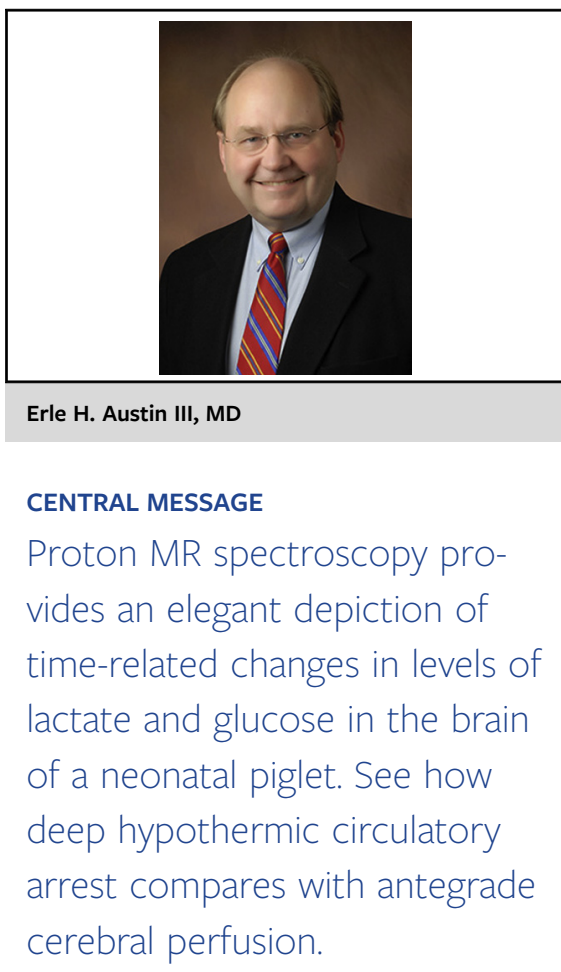

in the DHCA animals. Nevertheless, this application of proton MR spectroscopy with depiction of time-related changes in brain metabolites is an elegant presentation of what we would predict.

This report does not provide findings regarding any measure of neural injury. Although this study confirms that brain metabolism is significantly influenced by DHCA, if there is recovery without injury, the technique may still be applicable under appropriate circumstances clinically. The 60-minute circulatory arrest time employed here is longer than what most surgeons would utilize intentionally but might occur when unanticipated technical challenges present themselves. This use of proton MR spectroscopy in a cardiopulmonary bypass model is new and intriguing. It is hoped that the investigators will use this elegant view of the brain to explore variations of the support techniques described and examined in this report.

\section{Reference}

1. Hanley FL, Ito H, Gu M, Hurd R, Riemer RK, Spielman D. Comparison of dynamic brain metabolism during antegrade cerebral perfusion versus deep hypothermic circulatory arrest using proton magnetic resonance spectroscopy. J Thorac Cardiovasc Surg. 2020;160:e225-7. 